\title{
Transformation And Reactivation: The Research Of YuGur Women's Clothing Under The Digital Media Ecology
}

\author{
Zhang Zhi Teng ${ }^{1}$ \\ ${ }^{1}$ Northwest Minzu University
}

\begin{abstract}
Absrtact: National Culture is always embedded with specific space, which supports the field value of cultural. The evolution of minority culture has always been tightly around the specific regional space. The costumes of southern Yugur nationality in GanSu province have always been the most obvious symbol of their culture in the history of their development. In recent years, with the continuous evolution of the mode of spread, especially the digital media-based media ecological intervention in daily life, so that our traditional perception of the habit has quietly shifted. It is urgent to find a new way for the dissemination and re-activation of Yugur people costume culture in southern Yugur nationality in GanSu province under the digital media ecology. Focusing on the dilemma, transformation of Yugur people costume culture with VR take it re-activation, trying to find a new way to the costume culture of Sunan Yugur People in Gansu Province under the digital media ecology, making theoretical expiorations.
\end{abstract}

\section{Introduction}

Mirtsov, in 'the reader of Visual Culture', cites Paul's definition of photography, arguing that photography ownself carries a dialectical logic. This dialectical logic in series the past and the present in a circular narrative. From this point of view, we can see that the development of national costume, and also find it in this dialectical logic, but we pay more attention to its display as a cultural fossil. Here, its past is a sort of added value. Therefore, what we want to study is not the cultural characteristics of national dress itself, that is what is the discourse that causes this phenomenon, and how do we coordinate the relationship with it in the present media ecology.

\section{The desquamate of the "Physical Property" of Yugur women's clothing}

As a symbol, the value of costume itself is connected with the field where it came into being. As far as this is concerned, the historical construction of clothing comes from two decisive factors, one is the physical trace, the other is the relationship with different possessors. These guarantee the basis of the existence of costume history, and then, clothing as a specific cultural representation of the starting point. As "from the clothing can be seen the development track of national culture, the past dynasties linPen style, class relations, folk customs, cultural regulation... " [1]. From this point of view, clothing is a specific period of human cultural ecology of the calibration. Especially the costumes of the minorities. Yugur women's clothing is one of the few existing national costumes in Hexi, GanSu Province. Of course, we recognize that it has the function of characterizing the particular cultural ecology of the region, but let us think of it in a different way, as a texture of different possessiveness. Because while we think of it as a symbol of Yugur nationality culture, we take it out of the whole sequence of cultures to which it belongs. This extractity allows us to see that there is already a variation between Yugur people's costume and its cultural order. So what triggered the mutation?

At present, the display of culture in the minority areas in China is mainly spread by publications, exhibitions and festivals of specific ethnic cultures. In recent years, under the correct guidance of the Party and the government for national culture inheritance and protection consciousness, ethnic regions have started to build regional cultural type museums. At the same time, some scholars have begun to respond to this shift in theory. For example, Liu Zhu Rong, Guizhou Normal University's discussion on "the transformation of Minority Culture Communication" discusses the present situation, necessity and strategy of the transformation of minority culture communication, and how to realize the transformation. Yang Jin Yu, Kunming University, in his book "The protection and dissemination of ethnic cultural brands", argues that the most important way for spread ethnic culture is to create cultural brands in the context of the current emphasis on cultural industries. In particular, Shaanxi Normal University, Ma Rong's master's thesis, "The study of Yugur nationality Culture in the perspective of Media Change", investigates the Yugur People's Culture in Sunan Yugur Autonomous County from the perspective of positivism, finding it turns out that the spread of culture of Sunan Yugur Autonomous County has shifted from text publishing to the export of 
images, such as television. In this case, we can see that the cultural spread of minorities is facing a new veer, especially the emergence of new media, making this transformation has become an inevitable trend.

As a kind of living culture, national costume has become a kind of living historical relic, it even can be said that the costume is a national living history book. It not only has practical functions, but also more importantly, it is a walking living culture or sculpture. If we change the way of thinking, take the dress as a visual display of national culture, it is not impossible. As an important medium of the culture of Yugur women's dress, the trace of cultural overflow and integration are presented in this visual text.

However, the excessive use of the new media makes the media itself as a medium has jumped out of its own category, instead of the main body of spread. In turn, with the help of technology and constantly output is a variety of visual stimulation stunts. In this case, the Sunan Yugur people clothing dissemination is facing such a dilemma. How to use the new media to export national culture while keeping the national culture as the main body of spread?

The economic, social, cultural and other spheres of ZhangYe city, Sunan Yugur Autonomous County have undergone profound changes. The Yugur people in the region have diversified about their ideas, values and cultural identities and the social, cultural foundations on which the dress culture of Yugur people is based are very different from those of the past. At present, the research on women's dress in Yugur people mainly focuses on the characteristics, structure and pattern of dress, and the research on the combination of dress in Yugur people and virtual reality (VR) technology is extremely rare. In addition, the survival space of Yugur people's costume culture still depends on the national costume fair, Tourism Festival, as well as the ritual of life and festival within the ethnic groups to adhere to traditional elements and cultural connotations. In daily life, there are few Yugur people residents dress in traditional dress, either in the county seat of Sunan or marginal pastoral areas. The paper relies on VR simulation technology as the realization medium, through multi-dimensional information collection and digital display, changes people's appreciation form of Yugur women's clothing, through the transformation of digital media to create a sense of immersion and interactive experience, in order to sort out the deep-seated cultural significance of the evolution process, not only to achieve the digital protection function, but also more likely to expand the national culture of Innovative Heritage Vision.

\section{Technological shift of the revitalisation of women's apparel in Yugu nationality}

At present, Yugur Women's clothing display is still the main physical display, pictures, text, audio, video and other media forms as a supplementary way. "The virtual survival of the human being has made the part of the media environment, more visible and deeper than ever before. "[2]VR technology has changed the way that people appreciated Yugur people clothing, the immersion and interactive experience created by virtual simulation, not only makes the inheritance of the national culture not limited by time and space, but also a assist and supplement to the traditional protection mode which is the core of passing on the population for hand-to-hand.

VR depicts the specific knowledge points and details of Yugur People's costume culture with a more vivid and diversified way, and enables the audience to receive knowledge in the context of sound imitation. VR Constructs a cultural scene in which history and civilization are simulated, so that the concept of culture can be embodied in the process of spread without being limited by geography, space and time. The audience directly participates in the historical reappearance of the national costume culture, which makes the characterization of experience of the culture more profound and concrete, and further strengthens the understanding of the profound significance of the culture. It can be said that VR technology has changed the experience mode of the audience and deepened the experience of the audience. Instead of passively accepting text or video clips from traditional media, the audience can actively choose to access the Yugur People VR interactive system, as a participant, you can experience a certain aspect of the costume culture and gain a deep understanding of the costume.

\section{Virtual weaving of women's apparel in Yugu nationality}

As a medium of interaction between human and virtual space, interface itself is a kind of conversion of computer language. This transformation is based on the principle of human cognitive logic, and then, the interface becomes a kind of portal. Throughing the interface, the viewer enters the absent presence, thus establishing the cognition of the space itself. The change that VR technology is bringing to the interface today is that it no longer exists in a specific space in front of the human eye, keep a consistent balance harmony with the human body. In other words, it embedded in the human body, seems to have become an extension of the human body organs. Based on this, the change of media mode will bring about the replacement of "truth" itself, which will also influence the spread of national costume culture.

"The protection and inheritance of the intangible cultural heritage should consider not only the value connotation of immateriality, but also the protection, integrity and authenticity of various material forms. " [3] with the support of VR technology, the 3D model, video, audio, picture and text data are mixed in the virtual scene, and the mixed mode of the scene is set up and displayed harmoniously, to achieve the historical evolution of clothing, pattern features, process and other details of the expression, as well as the existent cultural state of clothing, even clothing-related raw materials and Folk life-style of the interactive function of reproduction. VR technology improves the efficiency of cultural transmission. After the image and character of costume culture were transformed into digital code by VR 
software technology, the accuracy of data is improved, so the uncertainty in the process of costume culture spread is reduced, it is also the extension of information collection storage to living knowledge. For example, clothing data measurement and structure restoration and so on. As the consciousness and thinking of the viewer coexist in the virtual environment, make the real-time interaction of information between the individual and the visual object is implemented to avoid the communication gap and obstacles, thus realizing the precision and continuity of the costume culture, this reinforces the effectiveness of the feedback.

Obviously, VR technology is a way of reassembling reality and remaking it as it is. For the spread of the national dress culture of Sunan Yugur Autonomous County, its role is no longer confined to the geographical boundaries of Sunan region, but a new and ubiquitous cultural geography. With the help of computers and the Internet, this simulacrum of Sunan Yugur Autonomous County dress actually destroys the dress itself as a physical object, instead using the woven visual images of computer language as objects for the viewer to interact. It can be seen that this presentation of Yugur People's clothing culture is the product of virtual weaving.

This dissolution of the materiality of clothing does not mean uprooting it from its original cultural lineage, making it an isolated object. this kind of virtualization of clothing in a certain extent, has broken through the clothing as a physical object, placed in the glass booth closed, or made into images broadcast on television and other media. These modes of communication limit the experience of clothing, as well as the wearability of clothing. It is worth that this mode of spread between the dress culture and the audience has always been in a dependent depend on the imagination to establish a relationship between the interactive state. Therefore, this kind of display or the dissemination way and between the viewer is still one kind of subject-object dichotomy relations. But with the introduction of VR, there is no distinction between the host and the guest. As an object, national dress becomes an object that can be experienced at any time, or a substitute. Thus, VR actually presents a new kind of "reality" for perception. Rather than calling the viewer a receiver, we might as well call it a user.

\section{Development of apparel VR display system}

Based on the above, we can see that the development of a set of Sunan Yugur Autonomous County clothing VR exhibition and Interactive Media System, is particularly urgent. In the process of constructing the framework of Yugur women's clothing VR interactive platform, consider develop the system's cost and cycle, platform universality, effective man-machine interaction, 3D simulation effect, dynamic browsing and quick operation, etc. , The system rely on the 3D simulation software platform of 3DS Max and the 3D interactive platform of VRP-BUILDER to integrate completely. To achieve multi-angle and multi-level perspective functional requirements, picture text and virtual reality co-existing information needs, fully display the traditional clothing process of material and artistic aesthetic needs, the performance requirements of easy operation and smooth operation of the system as well as the visual requirements of cross-system platform release.

The VR system relies on the 3DS Max to create 3D images of women in Yugur nationality, including figures, costumes, accessories, living environment and process flow. The VRAY renderer is used to create all kinds of 3D lighting maps, so that the object can obtain more accurate light distribution, complete the simulation of static model design. In addition, based on the interactive features of VRP-BUILDER, design a three-dimensional interactive experience solution. Using the built in interactive behavior module and Network transmission function module, the 360 degree Panorama interactive function of the simulation model generated by the 3DS Max is realized, breaking the limitation of time and space, and developing online participation in various interactive experiences. Finally, the system is exported as .exe executable and web-based Browser publishing .htm File, so as to achieve the scene of clothing display. In the process of appreciation and study, people get rid of the restriction of space field, fully understand the historical track, inheritance process, craft and other attributes of the national costume. So as to improve the efficiency of cultural information transmission. As shown in figure 1 .

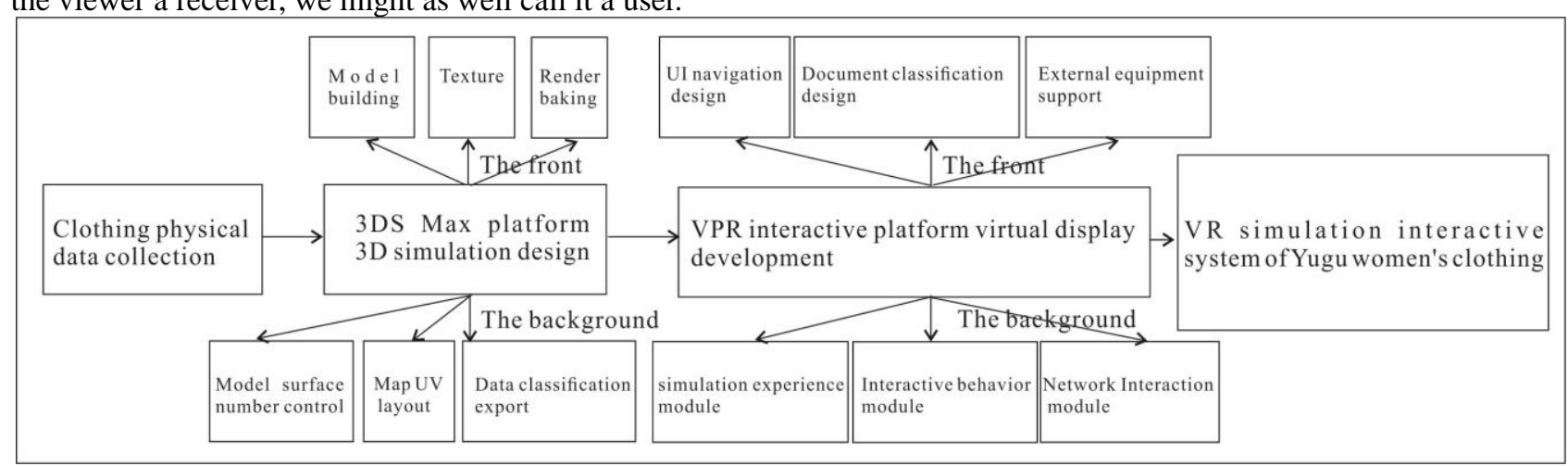

Figure 1: System flow diagram design

"whether it is to create a spatial illusion with the idea of imitation, or to perceive the inner distance through immersion, the construction and experience of artificial nature or fictional scenes can be found in the history, Is the ancient and Modern Chinese and foreign artistic idea and the Technical Union development may touch one big ideal ... By placing people in the scene of the form of expression to create a sense of presence full of reality, but more interesting is to bring more than the real experience, and form a cognitive experience." [4] and the 3ds Max 3d 
simulation platform realizes the visual simulation experience of Yugur women's clothing, can take dress and ornaments on the important pattern symbols to show to the world, convey the national dress aesthetic needs and creative ideas and other important information.

Take a model of women's clothing for example, 1 After a detailed study of the data and sample characteristics (style, structure, size, pattern, colour and texture) of the main components of Yugur women's dress and accessories( Gown, head and face, boots, red tassel, belt), make accurate structural drawings.2 The 3D character structure model is completed by the combination of 3ds Max polygonal technique and surface technique. Garment and accessories make 3D garment model according to 2D spline with GarmentMaker modifier, and then simulate the garment model with Cloth modifier. In the process of making the model, we should try to reduce the number of faces and the number of overlapping faces, so as to make the interactive display more smooth.3 Using the technology of model texture mapping and model texture mapping in the plane drawing software to assist the making of all kinds of material texture mapping of the model, and finishing UV correction in $3 \mathrm{ds}$ Max, make the material texture match the model type, complete the simulation of the pattern, texture and color of the real fabric. 4 The resulting texture model is baked to produce the final simulation model using VRAY rendering technology. If the model does not reach the evaluation indexes of garment shape, structure detail, fabric color and texture proportion, the related model and texture parameters will be modified until the 360 degree holographic simulation model standard is finally reached. Figure 2.

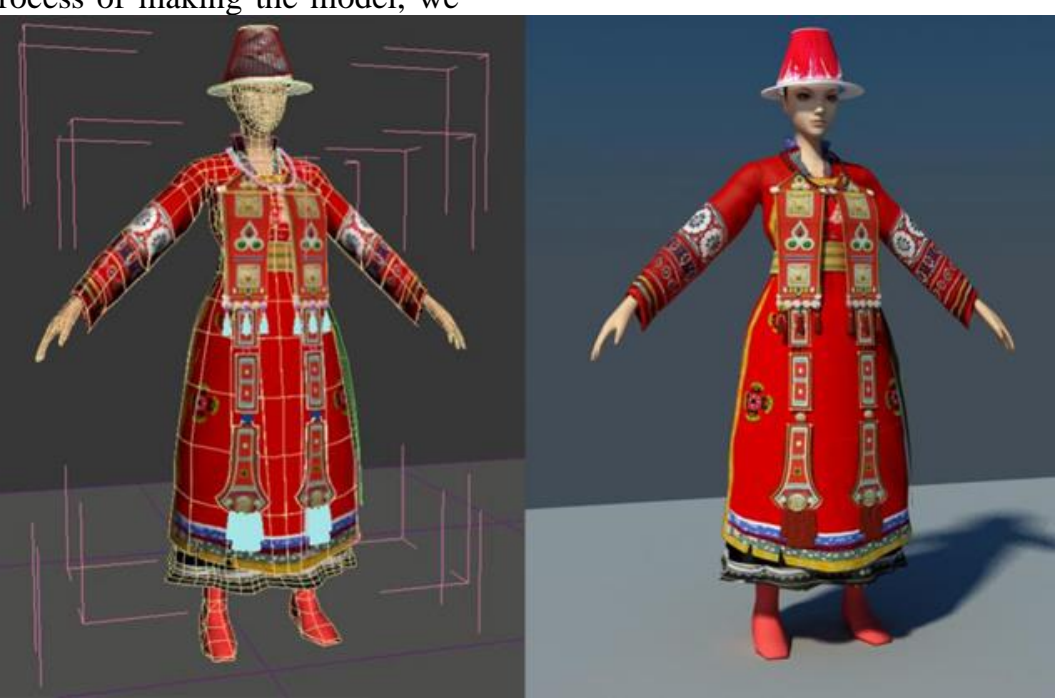

Figure 2: A mock-up of women's clothing in Yugur people

"human-computer interaction (HCI), when it proposed, refers mainly to human-computer interaction. Interaction design is the art of promoting human-human interaction through products and services." [5]The use process of simulation interactive products is the whole process of information circulation between people and products. This kind of frequent interaction between people and products forms a cycle in which people's cognition and thinking mode drive the interactive process. At the same time, people's vision, hearing, thinking habits, problem representation model. Through the application of VRP-BUILDER interactive function module, the display system can display the Yugur women's clothing in three-dimensional digital display and dress simulation, the visual and dynamic display of Yugur women's clothing creates an out-of-reality logical, comprehensive and cross-sensory relationship between the experiencer and the display system, thus forming effective feedback. The interactive display places the experiencer's perception in the central position, returns the shock and curiosity brought by the interactive technology to the corresponding aesthetic system, through the interactive experience makes the sense of interest and artistry continuously enhanced, thus for the national costume art to bring a deep sense of touching and admiration.

The user interface, as the most direct interface between the system and the user, not only presents the abstract information structure and interaction design to the user through a good visual way, it is also the guarantee that the simulation model made in $3 \mathrm{ds}$ Max can realize the virtual display through the interface interaction function design. By showing the setting of interactive framework, all kinds of data, such as clothing text information, simulation model, are classified and organized, and each information content put into the interactive framework in detail according to the setting of functions and levels. Model the display page includes a main page, five secondary sub-pages, twelve functional pages. Each level follows the principles of interaction behavior and vision, striving to achieve a clear and unified user interface of primary and secondary relationships. According to the browsing demand, the experiencer touches the related level button, pops up the related window, multi-touch controls the simulation hologram model under this level to realize the 360 degree interactive experience, in addition to various kinds of external connector wearing type equipment, the data glove blessing, it also completes the effective content of navigation, operation, feedback, perception and interaction, truly realizes the immersive display experience, realizes the intuitiveness, interaction and cooperation of the system interaction, thus deepens the memory of clothing culture. 


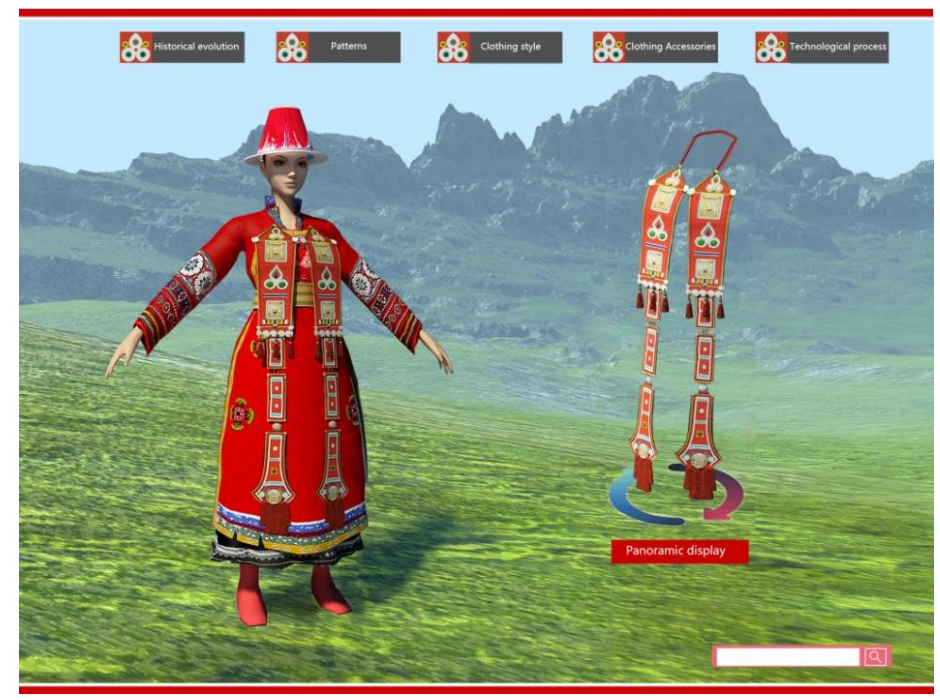

Figure 3: System home interface design

\section{Conclusion}

"See" does not mean what we see, but what we perceive. The act of viewing is actually participating in a complex field of perception, revising our perceptual experience, and participating in the transformation and retrieval of new perceptual experience. But this correction is based on computer graphics logic. VR actually acts as a "real" alternative to the physical dimension. The visualization of visual technology through data, that is the interface of VR acts as a door built digitally, only through this external organ embedded in our bodies, in order to realize the holistic experience and comprehensive interaction of perception. In this paper, the key technology of virtual display is discussed in detail, and the design and implementation of Yugur women's VR apparel display system is completed. It is hoped that through a beneficial attempt to integrate culture with science and technology, we can broaden our thinking for the protection of the traditional costume culture of Yugur women, so that the traditional national costume culture can have a better digital living environment, it makes the inheritance and development of this costume cultural heritage more meaningful and valuable.

\section{Acknowledgment}

Fund Project: This thesis is the result of the special fund project of the Basic Scientific Research Project of the Central University of Northwest University for Nationalities (No. 31920150111)

Zhang ZhiTeng (1982 -), Male, from Jiuquan, Gansu, school of Educational Science and Technology of Northwest Minzu University, Lecturer, Research Interests: 3-d animation design, virtual reality simulation design Contact telephone: 18609315661 Mailing address: Building21, Zhonghai Triumphal Arch Community, Lanzhou City, Gansu Province

\section{Notes:}

[1] Shen Congwen. Research on Ancient Chinese Costumes.Shanghai: Commercial Press, p. 2011.1

[2] Nie Youbing. The Final Spread of virtual Reality.Beijing: China Development Press, pp. 2017.75

[3] Liu Zhenghong. Research on digital Application and Educational Inheritance of Intangible Cultural Heritage.Beijing: China Light Industry Press, pp. 2018.67

[4] Wu Nani. Research on Interactive Art Design of Immersive Virtual Reality.Beijing. Central Academy of Fine Arts,2019.19-20

[5] [USA] JennyPreece, [UK] YvonRogers, HelenSharp /, Liu Wei, Zhao Lu, Guo Qing, Kurxingguo/translation. Interaction Design: Beyond Man-Machine Interaction, Beijing: Machinery Industry Press, page 2018.6

\section{References:}

1. $\mathrm{Gu} \mathrm{Yi,} \mathrm{Zhai} \mathrm{Enhao.Application} \mathrm{of} \mathrm{interactive}$ information transfer in display design.Art Work, issue 06,2019

2. Gu Yi. Research on 3D Display Interactive System based on VR technology.Art Work, issue 03,2019

3. Ma Fenfen. Design and Implementation of Tibetan Clothing digital display system.Beijing: Beijing Institute of Fashion Technology,2015

4. Li Qian. Research on the Connotation, Inheritance and Protection of The Folk Culture of Yugu costume in Sunan. Chongqing.ChongqinBusiness University,2019 